Volume 8. No. 6, June 2020

International Journal of Emerging Trends in Engineering Research

Available Online at http://www.warse.org/IJETER/static/pdf/file/ijeter49862020.pdf

https://doi.org/10.30534/ijeter/2020/49862020

\title{
Chemical and Biotechnological Methods for the Production of Xylitol: A Review
}

\author{
Edy Subroto ${ }^{1}$, Fitrah Hayati ${ }^{2}$ \\ Department of Food Industrial Technology, Faculty of Agro-Industrial Technology, Universitas Padjadjaran, \\ Jl.Raya Bandung-Sumedang Km. 21, Jatinangor, Sumedang 40600, Indonesia \\ 1'edy.subroto@unpad.ac.id, ${ }^{2}$ fitrahhayati118@gmail.com
}

\begin{abstract}
Xylitol is a type of alcohol sugar that is often used in various pharmaceutical and food industries. Xylitol can be produced from raw materials that contain lots of hemicelluloses. Hemicellulose is commonly found in various agricultural wastes such as bagasse, corncobs, oil palm bunches, and others. This review discusses various methods for xylitol production. In general, the production of xylitol uses chemical and biotechnological processes. Chemical production is generally carried out by hydrolysis using chemical catalysts or metals, while the biotechnological production is carried out by enzymatic and fermentation utilizing the role of microorganisms. Xylitol production in biotechnological methods has been developing rapidly to replace chemical production because xylitol yields are high and are environmentally friendly.
\end{abstract}

Key words: Xylitol, hemicellulose, xylose, sweetener, biotechnology.

\section{INTRODUCTION}

Xylitol $\left(\mathrm{C}_{5} \mathrm{H}_{12} \mathrm{O}_{5}\right)$ is a natural sweetener used in foods as a substitute for sucrose due to its sweetness and low-calorie content [1]. It is a pentose alcohol sugar, which is usually used as a substitute for sugar because xylitol has mainly benefits related to functional effects on health [2]. Xylitol has several advantages when applied to the chemical, pharmaceutical, and food industries [3]. Xylitol has been widely applied to various formulations in the food industry, especially in the confectionery, bakery, and pharmaceutical industries [4], [5]. Xylitol has good sweetening properties for health because it has the activity and ability to inhibit the microorganisms and shows the presence of anti-carcinogenic properties [2]. Xylitol has been proven to provide various health effects, especially for teeth and different other organs such as skin, digestive tract, bones, ear nose, throat, immune function, and weight management [6].
Xylitol can be produced from organic materials that contain high amounts of xylose sugar [2], [3]. Xylose-rich hemicellulose hydrolyzate has been developed as a substrate for producing xylitol [7]. Xylose is a component of hemicellulose. Material containing hemicellulose can be used as a raw material for producing xylitol. Besides, xylose can be modified into various kinds of derivative components other than xylitol, including furfural, propanol, acetoin, succinic acid, lactic acid, butanol, ethanol, acetic acid, acetone, butyric acid, and 2,3-butanediol [8].

Various agriculture-based industries produce waste or by-products that usually still precious of lignocellulose or materials containing pentose sugar and hemicellulose in large quantities [7]. Some ingredients that contain high pentose sugar include cornhusk and bagasse. Cornhusk is a by-product of corn milling. It contains pentosan, which is rich in arabinoxylan, which can be used as a raw material for the production of xylitol [2]. While sugarcane bagasse, which is the residue of the sugarcane extraction process, is a source of biomass rich in lignocellulose for the production of biofuels and additional sweeteners such as xylitol [9].

Xylitol can be produced chemically, thermo-chemically, and biotechnologically. At present, xylitol production is generally carried out chemically [2]. Industrially, xylitol is produced by chemical hydrolysis and xylan hydrogenation [10], followed by the reduction of xylose derivatives from hemicellulose hydrolysates. Chemical processes require catalysts such as ruthenium, palladium, and nickel at high temperatures $\left(80-140{ }^{\circ} \mathrm{C}\right)$ and high pressures $( \pm 50 \mathrm{~atm})$, thus requiring high energy and costs [7]. Chemical processes are usually expensive and require a lot of energy because they use metal catalysts, which are costly and produce low selectivity resulting in the formation of L-Arabinitol and other by-products [11]. As an alternative, xylitol can be produced biotechnological replacing conventional chemical processes [7]. Biotechnology or bioprocess production has developed rapidly for various synthesis or production of organic components such as protein modification into bioactive peptides [12], [13], modification of lipids into structured lipids [14], [15], and carbohydrate modification to modify starch and various types of sweeteners [16]. 
Edy Subroto et al., International Journal of Emerging Trends in Engineering Research, 8(6), June 2020, 2508 - 2512

In biotechnology, xylitol is produced by fermentation using microorganisms or enzymatic [17], [18]. The advantages of biotechnological production using both microbiology and enzymatic are relatively low temperatures, specific reactions, and does not cause environmental problems or are environmentally friendly [18], [19]. In general, microorganisms used in biotechnological production of xylitol are yeast. This review discusses various methods for xylitol production, especially by biotechnological processes using microorganisms.

\section{XYLITOL PRODUCTION}

\subsection{Chemical methods for the production of xylitol}

Chemical methods for xylitol production can be carried out through several stages, including hemicellulose extraction, hydrolysis of hemicellulose to xylose, and hydrogenation of xylose to xylitol [2]. The extraction of hemicellulose components can be conducted using Tetrabutylammonium hydroxide (TBAH) [20]. Hemicellulose-rich material mixed with TBAH then agitated at $50-70{ }^{\circ} \mathrm{C}$ for $60-120$ minutes, then centrifuged. The liquid fraction was adjusted to $\mathrm{pH} 4$, then stored overnight in cold temperatures $\left(4{ }^{\circ} \mathrm{C}\right)$ to precipitate hemicellulose. The liquid fraction was then centrifuged to collect hemicellulose. Furthermore, ethanol (95\%) was used to wash centrifuged pellets.

Isolation of the hemicellulose fraction can also be initiated by dewaxing the sample using a mixture of 50:50 ethanol/ toluene $(\mathrm{v} / \mathrm{v})$ for 2 hours to remove the lipid component. The dewaxed sample was then added with $\mathrm{KOH}$. The hydrolyzate obtained was then collected, and the $\mathrm{pH}$ adjusted to 5.5 by $\mathrm{H}_{2} \mathrm{SO}_{4}$, then $95 \%$ ethanol was added, and the solution was incubated at room temperature. The solids obtained were then washed using $75 \%$ ethanol and deionized water. Solids were collected through centrifugation after everything was washed and dried [2].

Hemicellulose obtained was then hydrolyzed by mixed with $72 \% \mathrm{H}_{2} \mathrm{SO}_{4}$ and refluxed at $30{ }^{\circ} \mathrm{C}$ for 1.5 hours [2]. The concentration of acid was then reduced by adding water. The mixture was then heated at $100{ }^{\circ} \mathrm{C}$ for 2 hours, then cooled, while the $\mathrm{pH}$ was adjusted to neutral $\mathrm{pH}$ by adding $\mathrm{NaOH}$ solution. Liquid sugar was then reduced by adding $\mathrm{NaBH}_{4}$. Xylose was concentrated in the hemicellulose fraction; therefore, hemicellulose from the sample needs to be isolated and used for the preparation of xylose extract. Isolates from the hemicellulose fraction were hydrolyzed using $\mathrm{H}_{2} \mathrm{SO}_{4}$ to release sugar. The hydrolyzate was then reduced using $\mathrm{NaBH}_{4}$ after the $\mathrm{pH}$ adjustment became neutral.

According to Delgado et al. [8], the chemical production process of xylitol, in general, is Lignocellulosic hydrolysis biomass rich in xylan with acid catalysts that will produce hydrolyzed rich in xylose. Xylose obtained was then purified and hydrogenated using $\mathrm{H}_{2}$ gas to produce xylitol. Xylitol obtained was then separated and purified, whereas thermochemical production is generally carried out by mixing samples with water and hydrolyzed in a reactor to release sugar at high temperature $\left( \pm 250{ }^{\circ} \mathrm{C}\right)$ at a pressure of about $27.6 \mathrm{MPa}$. The hydrolyzate was then reduced using hydrogen with a $\mathrm{Ru} / \mathrm{C}$ catalyst.

\subsection{Production of xylitol by biotechnological methods}

Hemicellulose-rich ingredients are pre-treated by hydrolysis of acid dilution and detoxification [3]. The sample was diluted using acid in a stainless steel reactor. Pre-treatment with acid dilution using different treatments. Dhar et al. [21] hydrolyzed acid dilution in sorghum by sulfuric acid at $121{ }^{\circ} \mathrm{C}$ for 70 minutes in the autoclave. The obtained biomass was then washed, and then the $\mathrm{pH}$ was adjusted to neutral by calcium carbonate followed by sodium hydroxide. The biomass was then concentrated to produce pentose (mostly xylose) by vacuum concentrator.

Jia et al. [20] hydrolyzed hemicellulose in acid dilution using $7 \%$ sulfuric acid, then heated $100{ }^{\circ} \mathrm{C}$ for 2 hours. The resulting hemicellulose hydrolyzate was collected using filtration and subsequently detoxified. In another study, Kumar et al. [11] hydrolyzed hemicellulose using $\mathrm{HNO}_{3}$ at concentrations of $0.25-1.5 \%$. The mixture was autoclaved for 30 minutes, then followed by cooling to stop the reaction. The precipitation results were removed by centrifugation at $10,000 \mathrm{rpm}$ for 15 minutes. The parameters that affect the hydrolysis process are $\mathrm{pH}$, temperature, and reaction time [11]. Acid dilution also causes changes in the sample cell wall [22]. The cell wall initially shows an uneven surface, surrounded by many filled cavities. Treatment with acids causes most cells to lignify on the inside of the cell wall matrix. $\mathrm{HNO}_{3}$ dilution treatment at high temperatures causes changes in the structure of the cell wall. The process of hydrolysis removes the amorphous component and changes the structure of crystalline. The loss of lignin results in the formation of pores because hydrolysis causes the damage of the cell wall resulting in swelling of the fiber and causes the formation of large hollow spaces [22].

Several methods can be used to improve product formation, including concentrated hydrolyzate is detoxified by $\mathrm{H}_{3} \mathrm{PO}_{4}$ and $\mathrm{CaO}$, then followed with the addition of charcoal powder. The final $\mathrm{pH}$ was adjusted to about 5.5 by sodium hydroxide [3]. Jia et al. [20] detoxified hemicellulose hydrolyzates using $5 \%(\mathrm{w} / \mathrm{v})$ of charcoal. The mixture was then filtered to segregate the charcoal. The $\mathrm{pH}$ was adjusted to 10 using calcium carbonate, then sodium sulfite was added, while the $\mathrm{pH}$ was adjusted to neutral by adding sulfuric acid. In another study, Kumar et al. [11] have successfully detoxified using ion exchange resins, namely hemicellulose hydrolyzate (nitrate) and the fermentation inhibitors (phenolic content) removed by the formation of a strong cationic ion exchange resins using A-15 hydrogen followed by A-15 hydrogen A-IRN78 strong anion ion exchange resin. 
Edy Subroto et al., International Journal of Emerging Trends in Engineering Research, 8(6), June 2020, 2508 - 2512

The detoxified hydrolyzate was then fermented using a bioreactor with different fermentation capacity based on the tools used. The fermentation process will produce xylitol. In addition to fermentation production, saccharification processes can also be carried out. Enzymatic saccharification was carried out on the shaker orbitals at temperatures of 30 ${ }^{\circ} \mathrm{C}, 200 \mathrm{rpm}$, with percentages of solids of $5-10 \%$. The enzyme used was Cellic CTec2 because it has high cellulase and hemicellulase activity. Samples were then analyzed using HPLC to determine the concentration and yield obtained [10].

In general, the process of producing xylitol by means of biotechnology includes the stages of acid dilution hydrolysis, detoxification, and fermentation or saccharification. The main problem in the process of producing xylitol in large quantities is the presence of inhibitors in the hydrolyzate [9]. Hemicellulose hydrolyzate contains a mixture of pentose and hexose sugars and other components that formed during the hydrolysis [7]. One way to increase xylitol productivity is by ultrasound-assisted xylitol fermentation [9].

Ultrasound-Assisted Xylitol Fermentation can be conducted in an Erlenmeyer flask placed in an ultrasound bath. Erlenmeyer flask was laid out in the middle of a bath sonicator that has been filled by water. The fermentation temperature was maintained at about $30{ }^{\circ} \mathrm{C}$ for a specified period. Fermentation was carried out until the residual concentration of xylose was reduced to less than $10 \%$. The use of sonication during fermentation shows that xylitol productivity has more than doubled [9].

Vaz de Arruda et al. [3] conducted a study to scale up the xylitol production with the yeast of Candida guilliermondii. The study was conducted using a pilot-scale with a bioreactor capacity of $125 \mathrm{~L}$ and compared with the lab-scale (2.4 and 18 $\mathrm{L})$. Measurement of kLa value was carried out in the absence of respiration of microorganisms. The fermentor was conditioned to fit the research needs, and the fermenter after it was filled with the medium, then oxygen was removed by nitrogen filling. The dissolved oxygen (DO) values were observed based on stirring conditions and airflow. The results showed that the conversion of xylose to xylitol could be raised with a minimum of conversion efficiency was about $60 \%$.

\section{MECHANISM OF FORMATION OF XYLITOL BY MICROORGANISMS}

Microorganisms that play a role in the formation of xylitol in the fermentation of hemicellulose biomass are various types of yeast. Some types of yeast used are Candida guilliermondii FTI 20037 and Debaromyces hansenii (NRRL Y-7426) [1], Candida tropicalis MTCC 184 [9], Candida guilliermondii FTI 20037 [3], Candida nepalensis [7], Candida magnolia TISTR 5663 [23], Komagatela pastoris [24], Saccharomyces cerevisiae PE-2 [10], Candida tropicalis MTCC 6192 [11], Candida tropicalis [20], [25], and Kluyveromyces marxianus ATCC 36907 [22].

According to Dhar et al. [21], apart from xylose, xylitol could also be produced from arabinose where xylose and arabinose were transported through microorganism cells. D-xylose was converted to xylitol in the presence of $\mathrm{NAD}(\mathrm{P}) \mathrm{H}$ dependent reduction. L-arabinose was converted to xylitol with a combination of L-xylulose reductase, D-psicose 3 epimerase, and arabinose isomerase. The reduction equilibrium of $\mathrm{NAD}(\mathrm{P}) \mathrm{H}$ in the reaction was produced by the pentose phosphate pathway. The production of xylitol in cells was excreted through unknown transporters. Fermentative xylitol production had been successfully carried out as a product of yeast fermentation that depends on several parameters such as the inoculum concentration, the presence of other contaminants or toxic contents, initial xylose concentration, temperature, $\mathrm{pH}$, and oxygen [3].

\section{YIELD OF XYLITOL}

Yield conversion of xylose to xylitol could be calculated based on the ratio between xylose consumption and xylitol concentration [3]. Xylitol yields from several studies, including Jia et al. [20], that producing xylitol from hemicellulose hydrolyzate corncobs in biotechnology using $C$. tropicalis CICC1779 obtained yields reaching $0.77 \mathrm{~g} / \mathrm{g}$. Fairuz et al. [22] produce xylitol from hemicellulose oil palm fronds (OPF) by biotechnological methods using $K$. marxianus ATCC 36907, yielding around $0.35 \mathrm{~g} / \mathrm{g}$. Whereas Vaz de Arruda et al. [3] produced xylitol using sugarcane bagasse as raw material, biotechnologically using $C$. guilliermondii, yielding around $0.66 \mathrm{~g} / \mathrm{g}$. Baptista et al. [10] producing xylitol from biotechnologically conditioned media using recombinant yeast of $S$. cerevisiae PE-2-GRE3 obtained yields reaching $0.99 \mathrm{~g} / \mathrm{g}$. Whereas Pappu and Gummadi [7] produce xylitol from Media + glucose $10 \mathrm{~g} / \mathrm{L}+$ xylose using $D$. nepalensis obtained yields reaching $0.54 \mathrm{~g} / \mathrm{g}$. Based on the xylitol yield data, it shows that the highest yield is in raw material with conditioned media and recombined yeast. Naturally, yeast $S$. cerevisiae cannot metabolize xylose, so recombination needs to be conducted first [10]. The increasing of xylitol yield can be performed by modifications to the xylitol production process are needed. Modifications are often used to improve the yield, nutritional, sensorial, and physicochemical properties of the products [26], [27], [28]. Modifications can be made starting from the preparation phase of hemicellulosic materials, purification technology or detoxification of xylose rich hydrolyzate, optimization of fermentation conditions by microorganisms or chemical catalyst selection and reaction conditions, xylitol purification obtained, and the crystallization process of xylitol [29]. Various studies to improve yield conversion from xylose to xylitol continue to grow. Xylitol has the potential to be a sweetener substitute for sucrose which is safe for consumption by diabetics. Diabetes has become a deadly disease and continues to increase throughout the world [30]. 
Edy Subroto et al., International Journal of Emerging Trends in Engineering Research, 8(6), June 2020, 2508 - 2512

\section{CONCLUSION}

The production of xylitol can be conducted both chemically and biotechnologically. Still, the biotechnological method has several advantages, especially the use of low temperatures, environmentally friendly, and it produces a higher xylitol yield. The combination of treatments in each production process can produce differences in the yield of xylitol produced where the yield in the biotechnological process using conditioned media and recombined $S$. cerevisiae show good effectiveness and high yields.

\section{ACKNOWLEDGEMENT}

The authors would like to thank to the Rector of Universitas Padjadjaran and the Ministry of Education and Culture of the Republic of Indonesia for the support provided.

\section{REFERENCES}

1. J. C. López-linares, I. Romero, C. Cara, and E. Castro, Xylitol production by Debaryomyces hansenii and Candida guilliermondii from rapeseed straw hemicellulosic hydrolysate, Bioresource Technology, vol. 247, no. July 2017, pp. 736-743, 2018. https://doi.org/10.1016/j.biortech.2017.09.139

2. S. Irmak, H. Canisag, C. Vokoun, and B. Meryemoglu, Xylitol production from lignocellulosics : Are corn biomass residues good candidates?, Biocatalysis and Agricultural Biotechnology, vol. 11, no. July, pp. 220-223, 2017.

https://doi.org/10.1016/j.bcab.2017.07.010

3. P. Vaz de Arruda, J. dos Santos, R. de Cássia Lacerda Brambilla Rodrigues, D. D. Da Silva, C. Yamakawa, G. de Moraes Rocha, J. Júnior, J. da Cruz Pradella, C. Vaz Rossell, and M. das Graças de Almeida Felipe, Scale up of xylitol production from sugarcane bagasse hemicellulosic hydrolysate by Candida guilliermondii FTI 20037, Journal of Industrial and Engineering Chemistry, vol. 47, pp. 297-302, 2017. https://doi.org/10.1016/j.jiec.2016.11.046

4. S. Ur-Rehman, Z. Mushtaq, T. Zahoor, A. Jamil, and M. A. Murtaza, Xylitol: A Review on Bioproduction, Application, Health Benefits, and Related Safety Issues, Critical Reviews in Food Science and Nutrition, vol. 55, no. 11, pp. 1514-1528, 2015. https://doi.org/10.1080/10408398.2012.702288

5. S. I. Mussatto, Application of Xylitol in Food Formulations and Benefits for Health, in D-Xylitol: Fermentative Production, Application and Commercialization, S. S. Da Silva and A. K. Chandel, Eds. Berlin Heidelberg: Springer-Verlag, 2012, pp. $1-345$

6. K. Salli, M. J. Lehtinen, K. Tiihonen, and A. C. Ouwehand, Xylitol's health benefits beyond dental health: A comprehensive review, Nutrients, vol. 11, no. 8, 2019. https://doi.org/10.3390/nu11081813

7. J. S. M. Pappu and S. N. Gummadi, Effect of cosubstrate on xylitol production by Debaryomyces nepalensis NCYC 3413: A cybernetic modelling approach, Process Biochemistry, vol. 69, no. February, pp. 12-21, 2018.

https://doi.org/10.1016/j.procbio.2018.03.023

8. Y. Delgado, O. Daniel, V. García, D. Mandelli, W. Alves, L. Antônio, and M. Pontes, Xylitol : A review on the progress and challenges of its production by chemical route, Catalysis Today, no. July, pp. 0-1, 2018. https://doi.org/10.1016/j.cattod.2018.07.060

9. B. Z. Tizazu, K. Roy, and V. S. Moholkar, Ultrasonic enhancement of xylitol production from sugarcane bagasse using immobilized Candida tropicalis MTCC 184, Bioresource Technology, vol. 268, no. July, pp. 247-258, 2018. https://doi.org/10.1016/j.biortech.2018.07.141

10. S. L. Baptista, J. T. Cunha, A. Romaní, and L. Domingues, Xylitol production from lignocellulosic whole slurry corn cob by engineered industrial Saccharomyces cerevisiae PE-2, Bioresource Technology, vol. 267, no. July, pp. 481-491, 2018. https://doi.org/10.1016/j.biortech.2018.07.068

11. V. Kumar, M. Krishania, P. Preet, V. Ahluwalia, E. Gnansounou, and R. S. Sangwan, Efficient detoxi fication of corn cob hydrolysate with ion-exchange resins for enhanced xylitol production by Candida tropicalis MTCC 6192, Bioresource Technology, vol. 251, no. November 2017, pp. 416-419, 2018. https://doi.org/10.1016/j.biortech.2017.11.039

12. E. Subroto and M. A. H. Qonit, Modification of soy protein for the production of bioactive peptides and their utilization, International Journal of Scientific and Technology Research, vol. 9, no. 2, pp. 3121-3127, 2020.

13. B. Rezaharsamto and E. Subroto, A Review On Bioactive Peptides Derived From Various Sources Of Meat And Meat By-Products, International Journal of Scientific and Technology Research, vol. 8, no. 12, pp. 3151-3156, 2019.

14. B. H. Kim and C. C. Akoh, Recent Research Trends on the Enzymatic Synthesis of Structured Lipids, Journal of Food Science, vol. 80, no. 8, pp. 1713-1724, 2015. https://doi.org/10.1111/1750-3841.12953

15. E. Subroto, M. F. Wisamputri, Supriyanto, T. Utami, and C. Hidayat, Enzymatic and chemical synthesis of high mono- and diacylglycerol from palm stearin and olein blend at different type of reactor stirrers, Journal of the Saudi Society of Agricultural Sciences, vol. 19, no. 1, pp. 31-36, 2020. https://doi.org/10.1016/j.jssas.2018.05.003

16. A. F. Hernández-Pérez, F. M. Jofre, S. de Souza Queiroz, P. Vaz de Arruda, A. K. Chandel, and M. das G. de A. Felipe, Biotechnological production of sweeteners, in Biotechnological Production of Bioactive Compounds, 
Edy Subroto et al., International Journal of Emerging Trends in Engineering Research, 8(6), June 2020, 2508 - 2512

M. L. Verma and A. K. Chandel, Eds. Amsterdam: Elsevier B.V, 2020, pp. 261-292.

17. E. Mardawati, M. T. A. P. Kresnowati, R. Purwadi, Y. Bindar, and T. Setiadi, Fungal Production of Xylanase from Oil Palm Empty Fruit Bunches via Solid State Cultivation, International Journal on Advanced Science, Engineering and Information Technology, vol. 8, no. 6, pp. 2539-2546, 2018. https://doi.org/10.18517/ijaseit.8.6.4196

18. E. Mardawati, R. Andoyo, K. A. Syukra, M. Kresnowati, and Y. Bindar, Production of xylitol from corn cob hydrolysate through acid and enzymatic hydrolysis by yeast, IOP Conference Series: Earth and Environmental Science, vol. 141, no. 1, 2018. https://doi.org/10.1088/1755-1315/141/1/012019

19. E. Subroto, Supriyanto, T. Utami, and C. Hidayat, Enzymatic glycerolysis-interesterification of palm stearin-olein blend for synthesis structured lipid containing high mono- and diacylglycerol, Food Science and Biotechnology, vol. 28, no. 2, pp. 511-517, 2019. https://doi.org/10.1007/s10068-018-0462-6

20. H. Jia, T. Shao, C. Zhong, H. Li, M. Jiang, H. Zhou, and P. Wei, Evaluation of xylitol production using corncob hemicellulosic hydrolysate by combining tetrabutylammonium hydroxide extraction with dilute acid hydrolysis, Carbohydrate Polymers, vol. 151, pp. 676-683, 2016. https://doi.org/10.1016/j.carbpol.2016.06.013

21. K. S. Dhar, V. F. Wendisch, and K. Madhavan, Engineering of Corynebacterium glutamicum for xylitol production from lignocellulosic pentose sugars, Journal of Biotechnology, vol. 230, pp. 63-71, 2016. https://doi.org/10.1016/j.jbiotec.2016.05.011

22. S. Fairuz, A. Manaf, J. Jahim, S. Harun, A. Amru, and I. Luth, Fractionation of oil palm fronds (OPF) hemicellulose using dilute nitric acid for fermentative production of xylitol, Industrial Crops and Products, vol. 115, no. February, pp. 6-15, 2018. https://doi.org/10.1016/j.indcrop.2018.01.067

23. S. Wannawilai, Y. Chisti, and S. Sirisansaneeyakul, A model of furfural-inhibited growth and xylitol production by Candida magnoliae TISTR 5663, Food and Bioproducts Processing, vol. 105, pp. 129-140, 2017. https://doi.org/10.1016/j.fbp.2017.07.002

24. D. Araújo, F. Freitas, C. Sevrin, C. Grandfils, and M. A. $M$. Reis, Co-production of chitin-glucan complex and xylitol by Komagataella pastoris using glucose and xylose mixtures as carbon source, Carbohydrate Polymers, vol. 166, pp. 24-30, 2017. https://doi.org/10.1016/j.carbpol.2017.02.088

25. C. Zhang, J. Qin, Y. Dai, W. Mu, and T. Zhang, Atmospheric and room temperature plasma (ARTP) mutagenesis enables xylitol over-production with yeast Candida tropicalis, Journal of Biotechnology, vol. 296, no. October 2018, pp. 7-13, 2019. https://doi.org/10.1016/j.jbiotec.2019.01.026
26. R. Indiarto, B. Nurhadi, Tensiska, E. Subroto, and Y. J. Istiqamah, Effect of liquid smoke on microbiological and physico-chemical properties of beef meatballs during storage, Food Research, vol. 4, no. 2, pp. 522-531, 2020. https://doi.org/10.26656/fr.2017.4(2).341

27. T. V. Pershakova, G. A. Kupin, L. V. Mikhaylyuta, E. S. Yatsushko, S. M. Gorlov, and T. G. Prichko, Strawberry Treatment with Low Frequency Electromagnetic Fields, International Journal of Emerging Trends in Engineering Research, vol. 8, no. 3, pp. 705-709, 2020.

https://doi.org/10.30534/ijeter/2020/15832020

28. E. Subroto, T. Tensiska, R. Indiarto, H. Marta, and A. S. Wulan, Physicochemical and sensorial properties of recombined butter produced from milk fat and fish oil blend, Bioscience Research., vol. 15, no. 4, pp. 3733-3740, 2018.

29. D. Dasgupta, S. Bandhu, D. K. Adhikari, and D. Ghosh, Challenges and prospects of xylitol production with whole cell bio-catalysis: A review, Microbiological Research, vol. 197, pp. 9-21, 2017. https://doi.org/10.1016/j.micres.2016.12.012

30. A. E. A. Altoum, A. M. Babker, M. Ismail, and V. Lyashenko, A Study of Correlation Ratios for Lowand High-Density Lipoprotein in Comparison with Antioxidant Vitamins A, E, C at Different Levels of Glycosylated Hemoglobin among Type 2 Diabetes Patients, International Journal of Emerging Trends in Engineering Research, vol. 8, no. 3, pp. 638-644, 2020. https://doi.org/10.30534/ijeter/2020/05832020 